\title{
Annette Paatz. ¡Tengamos novelas! Literatura y sociabilidad en el siglo XIX (Chile y Argentina, 1847-1866). Madrid: Iberoamericana, 2021, 393 páginas
}

Wilfrido Suárez Meza

Suárez Meza, W. (2022). Annette Paatz. ¡Tengamos novelas! Literatura y sociabilidad en el siglo XIX (Chile y Argentina, 1847-1866). Madrid: Iberoamericana, 2021, 393 páginas. Revista de Filología y Lingüística de la Universidad de Costa Rica, 48(1), e48634. doi: https://doi.org/10.15517/rfl.v48i1.48634

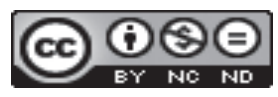

Doi: https://doi.org/10.15517/rfl.v48i1.48634

URL: https://revistas.ucr.ac.cr/index.php/filyling/index 
Revista de Filología y Lingüística de la Universidad de Costa Rica

ISSN: 0377-628X

ISSN: 2215-2628

filyling@gmail.com

Universidad de Costa Rica

Costa Rica

\title{
Annette Paatz. iTengamos novelas! Literatura y sociabilidad en el siglo XIX (Chile y Argentina, 1847-1866). Madrid: Iberoamericana, 2021, 393 páginas
}

\author{
Suárez Meza, Wilfrido \\ Annette Paatz. ;Tengamos novelas! Literatura y sociabilidad en el siglo XIX (Chile y Argentina, 1847-1866). \\ Madrid: Iberoamericana, 2021, 393 páginas \\ Revista de Filología y Lingüística de la Universidad de Costa Rica, vol. 48, núm. 1, e48634, 2022 \\ Universidad de Costa Rica, Costa Rica \\ Disponible en: https://www.redalyc.org/articulo.oa?id=33268016014 \\ DOI: https://doi.org/10.15517/rfl.v48i1.48634
}

\section{(c) (1) (9)}

Esta obra está bajo una Licencia Creative Commons Atribución-NoComercial-SinDerivar 3.0 Internacional. 
Annette Paatz. ¡Tengamos novelas! Literatura y sociabilidad en el siglo XIX (Chile y Argentina, 1847-1866). Madrid: Iberoamericana, 2021, 393 páginas

Wilfrido Suárez Meza

Briar Cliff University, Iowa, Estados Unidos

Wilfrido.Suarez@briarcliff.edu

(iD https://orcid.org/0000-0003-3113-0871

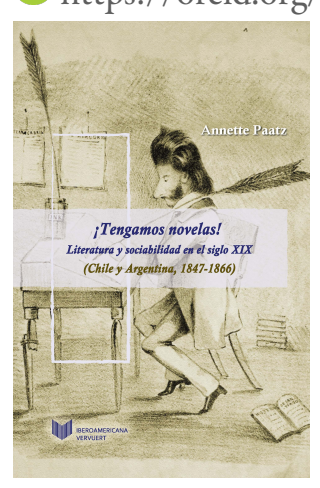

DOI: https://doi.org/10.15517/rfl.v48i1.48634

Redalyc: https://www.redalyc.org/articulo.oa? $\mathrm{id}=33268016014$
Paatz Annette. ¡Tengamos novelas! Literatura y sociabilidad en el siglo XIX (Chile y Argentina, 1847-1866). 2021. Madrid. Iberoamericana. 393 pp.

Al terminar nuestra académica lectura y empezar a reseñar la valiosa impresión informativa que nos deja el texto de iTengamos novelas! Literatura y sociabilidad en el siglo XIX (Chile y Argentina, 1847-1866), experimentamos, con agrado, la sensación de volver a deleitarnos escuchando, visualizando las palabras dictadas por la investigadora y estudiosa Annette Paatz en este magistral estudio de análisis y crítica literarios. La conjunción entre la palabra, la imagen y su pensamiento conversacional muestran el portento logrado por la investigadora y profesora de literatura en su estudio sobre las novelas chilenas y argentinas seleccionadas. De hecho, en su labor se hace realidad la meta idealizada por los y las grandes maestras en la historia grecolatina y del presente, lo de "enseñar deleitando", un logro mayor, este, el de Annette Paatz. Para mí en estos precisos y pandémicos momentos me ha sido aleccionador conocer a fondo el origen y desarrollo de la obra en su conjunto. De verdad, he disfrutado del placer de su lectura y me sumo a los ecos suscitados por las disquisiciones y pareceres encontrados aquí.

El libro lleva una sublime dedicatoria y abraza los cinco capítulos con una concisa introducción y directa conclusión en las que comparte algunos de los muchos logros que se encuentran dentro de esta excelente obra seminal en la que se analizan las novelas: Emma y Carlos o Los dos juramentos (1848) de Bernabé de la Barra, Los misterios de Santiago (1858) de José Antonio Torres, La aritmética en el amor (1860) de Albert Bless Gana, Alberto el jugador (1860) de Rosario Orrego, Soledad (1847) de Bartolomé Mitre, Esther (1858) de Miguel Cané, El médico de San Luis (1860) de Eduarda Mansilla y El Hogar en la Pampa (1866) de Santiago Estrada. Los estudios realizados al investigar cada una de estas novelas muestran un claro dominio y saber epistemológico de la narratología y son avalados por los doctos intercambios intelectuales que la autora mantiene con la crítica especializada en la que apoya su investigación y parecer personales. Valiosos son también sus aportes como el hecho de compartir algunos de los apreciables documentos literarios en el Apéndice del libro; asimismo, el manejo de las ideas sacadas de la teoría literaria y de los desplegados filosóficos posmodernistas; puesto que le permiten lograr explicarle al lector completa y detalladamente lo que ha estado trabajando y lo que ha logrado aportar con su estudio, del que citamos algunos ejemplos y citas textuales: "Los recursos narratológicos empleados corresponden a la funcionalización del género.", "Comúnmente, la 
instancia narradora heterodiegética vincula lo narrado con la realidad extratextual; en los casos de Torres, Estrada y, aunque de otra forma, también de Cané, se llega incluso a quebrantar la diégesis.", "Las referencias intertextuales explicitas a hipotextos europeos (Torres, Mitre, Mansilla), en vez de ser simples imitaciones, se ajustan de manera productiva a las respectivas circunstancias.", entre otras observaciones.

Como cuando se demuestra el énfasis en lo local por los autores y que pudo observarse al analizar el texto de Mitre al enfatizar su idea por crear una literatura "americana": "Mitre se apropió del esquema de la literatura romántica para pronunciar su posición con respecto a las condiciones sociales contemporáneas, abarcando tanto la descripción del estilo de vida como la construcción de una estructura familiar que corresponde al proyecto fundacional todo ello sin salir del registro de lo moralmente admisible".

¡Tengamos novelas! Literatura y sociabilidad en el siglo XIX (Chile y Argentina, 1847-1866) es una obra investigativa de gran alcance y que aporta grandes novedades al estudio de la narrativa decimonónica por los aspectos renovadores y que complementa estudios anteriores fundacionales y costumbristas con las propuestas de "la funcionalización política de la literatura" y/o creaciones femeninas contestatarias, y de género sexual como las que ha descrito lograron hacer Rosario Orrego y Eduarda Mansilla: "En las escritoras femeninas, se pudo observar que su actividad en la vida cultural podía resultar mucho más combativa de lo que su recatado discurso literario dejaría suponer". Casi para finalizar su dictamen literario Annette Paatz nos recuerda aquello visto en el despertar del siglo XIX: "Los veinte años que abarca la producción novelesca discutida nos procuran una visión sorprendentemente inmediata de la época y de su confianza todavía no desilusionada en el potencial de la civilización”. En suma, la renovación y el alcance de las ideas expresadas en ;Tengamos novelas!... justifican su inserción dentro del mundo literario y de la crítica especializada por derecho propio. Tal vez pareciera la mía una opinión tomada a la ligera pero no es así, el trabajo literario de alto nivel avala este parecer. Esta es una reseña llena de admiración por el valor ilustrado y por el personal de una palabra que se expresa clara, sucinta y sabiamente; una voz joven que sacude a la crítica literaria y que ha llamado la atención por sus aportaciones a los estudios sobre la narrativa del siglo XIX suramericano. Ideas que valen lo que muestran: "la novela se vincula con las condiciones extratextuales", o "La novela se convirtió en un requisito del estilo de vida, por lo cual también se reforzó su programática prescriptiva". Asimismo, que "la práctica novelesca se hubiera dedicado precisamente al costumbrismo" o "anclada en estructuras patriarcales" y de que "en Latinoamérica las culturas populares y de élite se negociaban en un mismo espacio discursivo". Estas agudas observaciones acerca de la importancia y fuerza mediática de la novela en el periodo citado en ambos países las vuelve a constatar al tensionar la poca producción creada y la enorme penetración cultural que la crítica literaria y la prensa tienen, en especial el periodismo, tuvieron en la vida social cultural económica y política americana: "se ha confirmado rotundamente la funcionalización política de la literatura; esta compartió con la política los mismos lugares mediáticos, del mismo modo que los autores tratados reunieron en su persona actividades políticas como literarias".

La realidad del siglo XIX chileno y argentino es representada viva y, literalmente, explicada en ;Tengamos novelas! Literatura y sociabilidad en el siglo XIX (Chile y Argentina, 1847-1866) con una gran verosimilitud por estos y estas novelistas que en sus obras de creación plasman la vida en Santiago de Chile y las provincias argentinas. Esta es la impresión que queda al entrar en contacto con los escritores y lectores de estas novelas rescatadas por la docta investigadora y al todavía mucho más al ver el manejo que ella hace del mundo de la ficción decimonónica americana y la manera en la que maneja a sus colegas suramericanos y europeos; es decir, sus pares contemporáneos. La certeza en sus opiniones, van en consonancia con el conocimiento adquirido a lo largo de su carrera profesional; sobre todo por el enorme peso de la crítica subjetiva y el valor inquisitivo y contestatario desplegado por Annette Paatz, quien desde el principio nos comparte sus versadas opiniones al enfrentar los desafíos intelectuales y sociales al estudiar a la narrativa y decir que: "En vista de la producción novelesca relativamente reducida en el periodo investigado, considero que el corpus seleccionado alcanza un grado de representatividad que posibilita sacar conclusiones generalizadoras sobre la practica novelesca argentina y chilena del siglo XIX”. Ese breve compendio literario estudiado no le impide sacar sus 
comentarios e ideas en torno a la novelística estudiada por ella; por ejemplo, al referirse a Alberto el jugador, Annette Paatz nos constata su dominio ante la crítica literaria y juicios literarios con los que apoya sus ideas: "la novela también muestra que los empleados de las nuevas clases medias tienen muy pocas posibilidades de mejoramiento material en la nueva sociedad capitalista [...] Sin embargo alude a un clima de tensión social en el cual se percibe claramente la delimitación entre la aristocracia y las clases medias emergentes. El imaginario colectivo de la élite está marcado por la dinamización social y los intentos de distinción originados por ésta". Como se puede observar en cada uno de sus comentarios se mantiene un tono sincero, directo, amable que disfruta su labor juiciosa y comparte el profundo conocimiento que tiene de la literatura estudiada y del descubrimiento de las realidades y vidas del pasado para la crítica actual.

¡Tengamos novelas! Literatura y sociabilidad en el siglo XIX (Chile y Argentina, 1847-1866) es un texto fundamental que está lleno de observaciones, reflexiones, pensamientos, conversaciones, posiciones, giros y juegos lingüísticos ilustrados y estructurados de tal manera que invitan a mantener una completa atención en los juicios y descubrimientos logrados por la profesora Annette Paatz. Su libro muestra un gran compendio de registros periodísticos y culturales de la época estudiada; asimismo, va acompañado de citas literarias tomadas de los textos originales para incrementar el valor literario e histórico de las obras estudiadas. No podemos dejar de resaltar los planteamientos críticos y aportaciones que los afamados teóricos y críticos de la literatura nacional e internacional nos ofrecen y que son sabiamente utilizados como contrapeso y para aumentar la calidad del estudio literario que nos comparte la brillante escritora.

Hacia el final del libro se describen, agudamente, parte de los conflictos y condiciones sociales en los que navegan los personajes, narradores y antagonistas de las novelas estudiadas: "Todos los textos del corpus estudiado se localizan en el registro liberal y retoman temas sociopolíticos prevalecientes: instrucción y educación, republicanismo, patriotismo, crítica de la nobleza, de la iglesia y de la jurisdicción antidemocrática, inmigración y colonización, el rol de las mujeres". En la estructura literaria binacional y bilingüe en la que se divide ;Tengamos novelas!... se insertan los estudios internacionales tanto de críticos y teóricos de Latinoamérica, de Europa, de la época estudiada y de los juicios literarios presentes, literales y virtuales con los que nace a pesar de los tiempos pandémicos. La síntesis literaria expresada por Annette Paatz nos lo confirma: "Los análisis están organizados en dos apartados sobre la producción novelesca chilena y argentina, respectivamente, cada uno de ellos consta de dos subcapítulos, que siguen un criterio cronológico y se dedican al análisis de cuatro novelas ejemplares y de sus contornos a fin de recuperar aspectos centrales de la práctica novelesca decimonónica".

El de Annette Paatz es, sin lugar a dudas, un completo estudio sobre la realidad social y cultural del siglo XIX vivida y expresada en la creación literaria y apoyado por los comentarios personales de los y las autoras, los registros periodísticos y de las antagónicas voces de la crítica literaria liberal y conservadora; es decir la naciente cultura de la alta y baja sociedad de ambas naciones suramericanas de la primera mitad del siglo sometidas a la valoración y juicio literario personal de la escritora. Por lo tanto, este excelente estudio crítico latinoamericano sobre la novela del XIX, amerita una lectura y difusión masiva en los centros académicos, culturales y en los circuitos y redes de la comunicación mundial. Este estudio sobre la novelística de Santiago de Chile y de las provincias argentinas marcará un antes y un después en los estudios de la novela y sacudirá a propios y extraños al mantener juicios de valor que rebasan el plano de lo subjetivo y que llegan de frente a cuestionar al canon literario elitista y fragmentado de la literatura latinoamericana contemporánea. Sinceramente es esta una entusiasta invitación a leer y disfrutar plenamente del esquema estructural, temático, teórico e inquisitivo conformado en ;Tengamos novelas! Literatura y sociabilidad en el siglo XIX (Chile y Argentina, 1847-1866). 